\title{
Cultura da performance
}

idéia de que os indivíduos devem se tornar integral mente responsáveis por suas próprias carreiras, destino e sucesso é parte de um credo que está na origem de uma nova cultura empresarial. Nessa cultura, valores como empreendedorismo, iniciativa, performancee autonomia foram eleitos como essenciais para demarcar a linha entre sucesso e fracasso. Este artigo anal isa os fundamentos desse credo eidentifica al gumas de suas principais conseqüências.

por Pedro F. Bendassolli GV-executivo

Há mais de cem anos, um dos filósofos mais influentes do último século advertia seus contemporâneos sobre a chegada de um indivíduo totalmente liberto dos valores morais. $\mathrm{N}$ ietzsche acreditava que este indivíduo seria capaz de responsabilizar-se integralmente por sua própria vida, desvencilhando-se de todo tipo de obrigação para com a tradição, os costumes e a religião.

0 tempo passou e a profecia nietzschiana parece ter se realizado. U ma rápida análise de al guns de nossos mais recentes hábitos culturais é suficiente para demonstrar que 
o indivíduo parece ser hoje o senhor soberano de seu destino. Tomemos, por exemplo, o caso da carreira profissional; hoje, é o indivíduo que a escolhe, e não seus pais, amigos, chefes ou professores. Tampouco parece concebível para o indivíduo permanecer em uma mesma empresa a vida toda, entregando a esta o curso de sua carreira; a permanência em um emprego depende de decisões que maximizem seus interesses e desejos.

0 exemplo anterior certamente não constitui caso isolado. Ele revela o surgimento de um novo credo, segundo o qual os indivíduos devem se tornar "empreendedores de suas próprias vidas". Este artigo irá, em um primeiro momento, apresentar os principais fundamentos desse novo credo ligado à cultura de negócios; e, em um segundo momento, discutir suas principais conseqüências, tanto negativas quanto positivas.

Mestres do desti no. Um dos fundamentos do novo credo da cultura de negócios é que o indivíduo deve assumir a responsabilidade integral por sua própria vida. Isso tem como pressuposto a perda da influência da tradição e dos val ores a ela ligados. Falar em tradição equivale a fal ar em cultura, que pode ser definida como um conjunto de regras e valores que oferecem aos indivíduos referenciais de orientação considerados seguros. 0 que esse novo credo apregoa é que os indivíduos não devem contar mais com esse suporte cultural. 0 indivíduo será bem-sucedido à medida que conseguir construir uma identidade pessoal que não dependa de nenhuma outra coisa que não seja sua própria ação pessoal.

\section{Um dos fundamentos do novo credo da cultura}

\section{de negócios é o de que o indivíduo deve assumir}

\section{a responsabilidade integral por sua própria vida.}

\section{Ele deve ser o "empreendedor de si mesmo".} ra a ela associada.

da família em que o indivíduo nascesse, sua vida estaria ara, se o indivíduo deve construir sua identidadem, para isso, contar com os referenciais dados pela

Altar profano. Para Ehrenberg, a forma como as sociedades ocidentais vêem a empresa mudou nas últimas três décadas (ver $\mathrm{Q}$ uadro). A empresa deixou de ser vista apenas como um lugar de exploração, símbolo extremo do capitalismo de concentração de renda, para se tornar um modelo a ser imitado. 0 mesmo aconteceu com os antigos chefes, que se transformaram em líderes e em modelos de realização para todos. De fato, os executivos são hoje vistos como indivíduos que incorporam características valiosas, tais como espírito empreendedor, iniciativa, ousadia, eficiência e autonomia.

Essa transformação ocorreu em paralelo à transformação no mundo dos esportes. Ao mesmo tempo em que os esportes são hoje conduzidos como negócios, as empresas se baseiam em modelos similares aos que regem a competição esportiva. Com isso, diversos princípios comuns na linguagem das organizações vêm dos esportes, materializados em expressões tais como "superar limites" e "vencer os adversários".

No Brasil, temos vários exemplos de esportistas empresários, que são respeitados e vistos como modelos de conduta. Esses indivíduos são comumente apresentados como casos de sucesso pessoal, pessoas que venceram com esforço, dedicação e dis-

Um segundo fundamento desse novo credo é o fato de que a identidade pessoal não é mais uma coisa que alguém adquire, mas sim constrói. Essa premissa é diferente da que existia em uma época na qual, dependendo ciplina. Tais model os induzem as pessoas a acreditar que o importante é assumir riscos, enfrentar desafios e vencer obstáculos por conta própria. Acredita-se que, ao agir assim, o sucesso virá naturalmente. 
Os perigos da excelência. Tais valores, e os comportamentos a eles associad os, geram diversos impactos. A primeira conseqüência do culto à performance é o fomento do que o sociólogo norte-americano Frank Furedi chamou recentemente de cultura da terapia. $\mathrm{Na}$ medida em que o indivíduo tem de reinventar-se a cada momento, seja na sua carreira ou na sua vida pessoal, ele precisa contar com a ajuda de especialistas. 0 papel desses especialistas é oferecer apoio, na forma de terapia, coaching ou consultoria. A cultura da terapia é problemática em duas situações: primeiro, quando torna 0 indivíduo dependente do apoio especializado; e, segundo, quando reduz e simplifica as causas de problemas a questões puramente individuais.

A segunda conseqüência do culto à performance relaciona-se com a pressão por resultados. Executivos e outros profissionais devem estar, a todo momento, em estado de vigilância e prontidão. Indivíduos expostos a tal condição podem vir a desenvolver quadros de estresse e, eventualmente, patologias graves - por exemplo, depressão.

A terceira conseqüência relaciona-se aos atritos resultantes das práticas empreendedoras. Ao mesmo tempo em que existe uma forte pressão pelo individualismo empreendedor, que leva à busca da diferenciação pessoal e da competição entre pares, ocorre uma outra pressão, contra mudanças do status quo e pela adoção de processos de acomodação grupal. Tal condição é acentuada no Brasil pelo caráter personalista que marca nossas relações. Por isso, o sucesso individual dependerá em grande medida da capacidade de estabelecer redes e cultivar relações. As pressões contraditórias poderão gerar atritos, conflitos e trazer resultados negativos para os indivíduos e para a organização.

Coexistência de humores. Entretanto, ao estimular valores voltados para a auto-realização e o empreendedorismo, a cultura do culto à performance pode também trazer conseqüências positivas. No Brasil, onde os serviços públicos são caros, ineficientes, corporativistas e autocentrados, a mentalidade gerencial, com seu conjunto de valores relacionados à performance, pode contribuir para a modernização dessas instituições e para o oferecimento de serviços de melhor qualidade à população.

\section{Num contexto como o brasileiro, em que as estruturas estatais são caras, inefici entes, corporativistas e autocentradas, a mental idade gerencial, com seu conjunto de valores relacionados à eficiência, pode contribuir para a modernização dessas instituições.}

O utra conseqüência positiva da disseminação de valores ligad os à performance é a possibilidade de um processo de transformação cultural mais abrangente. Alguns pesquisadores apontam que um traço forte de nossa cultura é o paternalismo. Em algumas empresas locais, 0 paternalismo se manifesta em formas rígidas de controle dos funcionários, que reagem com baixo comprometimento e baixo estímulo à inovação. Em tais condições, valores associados à performance podem gerar impactos sobre a cultura organizacional, levando à substituição de estilos anacrônicos de gestão por estilos mais abertos e participativos.

Contextos híbri dos. Embora se possa afirmar que 0 culto à performance represente "o espírito da época", não se deve assumir que se trata de um modelo monolítico. $N$ as empresas brasileiras, encontramos todo tipo de situação. Em um extremo, temos empresas anacrônicas, praticando modelos ainda focados no conceito de comando e controle, próprio do início do século passado. No outro extremo, temos organizações que absorveram totalmente os novos valores, colhem os frutos, porém também pa- 
gam preço alto por suas conseqüências negativas. Entre elas, temos todo tipo de caso, sendo o mais comum aquele no qual o discurso foi modernizado, embora as práticas ainda não o tenham acompanhado.
Pedro F. Bendassolli

Prof. de psicologia na Universidade Paulista

Doutorando em Psicologia Social na USP

E-mail: pedrofernando@terra.com.br

\section{Novos humores}

Em entrevista exclusiva à GV-executivo, o sociólogo francês Alain Ehrenberg fala sobre seu livro, que será lançado brevemente no Brasil, e sobre o novo humor que caracteriza a cultura empresarial de nossos dias.

Qual é a principal questão discutida no livro 0 culto à performance?

0 objetivo do livro é explicar que o culto à performance é uma maneira de enfrentarmos as transformações ocorridas na noção de igualdade. Em outras palavras: toda sociedade democrática possui princípios para resolver a contradição entre 0 justo e 0 injusto, entre igualdade de princípios e desigualdades reais: de oportunidades, de renda e de acesso ao poder. A sociedade francesa do pós-guerra, por exemplo, baseava-se em um modelo de igualdade que opunha concorrência e justiça, ou seja, era uma sociedade que buscava limitar as consequêencias negativas da concorrência, preservando a justiça na distribuição de recompensas e sanções. No entanto, ao longo da década de 1980, a sociedade francesa se converteu aos valores da concorrência, da competição e da conquista. Esportistas, aventureiros, inventores, profissionais autônomos, trabalhadores abrindo suas próprias empresas e outros "combatentes" tornam-se figuras populares. Um novo modelo de igualdade apareceu, um que fazia com que o que era considerado "justo" era um produto direto da concorrência. Pois é exatamente isso que representa a competição esportiva: ela é a única atividade social que encena a união harmoniosa da concorrência com a justiça. Ela é a própria imagem do que é uma igualdade justa. Roberto da Matta mostrou muito bem isso em relação ao futebol no Brasil. Os novos objetos de identificação e as novas normas tinham como elemento comum o fato de que saímos do mundo da disciplina para entrar no da autonomia.

0 que caracteriza esse novo humor, ou estado de espírito? Penso que três mudanças caracterizam esse novo estado de espírito. Primeiro, o proprietário de empresa, símbolo tradicional da dominação dos fortes sobre os fracos, pelo menos entre nós, na França, é escolhido como modelo de conduta para todos, ou seja, é considerado um modelo a ser imitado. Em segundo lugar, o consumo, que era a encarnação da massificação da classe média e da alienação das classes populares na década de 1960, recicla os valores dos movimentos de libertação da década de 1970 e se transforma num vetor de realização pessoal. Por último, 0 campeão esportivo, que até então era um herói anônimo entre as classes populares, é redefinido como um símbolo de excelência social. Na França, essas mudanças acontecem na década de 1980. A dupla utopia tradicional da esquerda, a sociedade assistencial e a alternativa ao capitalismo, não corresponde mais à realidade de uma sociedade em que se difundem, ao mesmo tempo, o ideal do sucesso social e o temor da exclusão.

0 que mudou na França nos últimos anos? 0 país se tornou mais empreendedor?

Hoje, empreender se tornou o único modelo de conduta possível. Em contrapartida, as desigualdades se mantêm, embora tenham mudado de estilo e de formato. Há hoje um novo debate sobre as desigualdades, pois em um mundo que promete, antes de qualquer coisa, o sucesso individual, as desigualdades são cada vez mais encaradas como uma falha pessoal. As expectativas aumentaram, mas não as possibilidades de realizá-las. $\mathrm{Na}$ prática, sabemos que a realidade da vida social não funciona com base em uma concorrência justa. Por isso há um ceticismo entre os trabalhadores com respeito ao tipo de contrato social promovido pelo novo estilo de igualdade, com base no qual eles têm de se aplicar no trabalho em troca da segurança de emprego e de uma carreira na empresa, ou seja, eles têm de trazer sua alma para trabalho, e não apenas seus braços e suor. Existe um sentimento crescente de precariedade, que atinge não somente os mais frágeis ou menos qualificados, mas também a classe média e os estratos superiores da sociedade. A ascensão do voto de protesto da extrema direita e da extrema esquerda na França exprime exatamente esse medo de enfrentar o futuro sem uma rede de proteção. 